\title{
As cores no ambiente de terapia intensiva: percepções de pacientes e profissionais
}

\author{
COLORS IN THE INTENSIVE THERAPY ENVIRONMENT: \\ PERCEPTIONS OF PATIENTS AND PROFESSIONALS
}

\section{LOS COLORES EN ELAMBIENTE DE CUIDADOS INTENSIVOS: PERCEPCIONES DE PACIENTES Y PROFESIONALES}

\author{
Nélio Barbosa Boccanera', Sulvia Fernandes Borges Boccanera ${ }^{2}$, Maria Alves Barbosa ${ }^{3}$
}

\section{RESUMO}

A utilização das cores no ambiente da Unidade de Terapia Intensiva - UTI pode interferir no bemestar dos profissionais e clientes. Este estudo teve como objetivo analisar percepções de profissionais e pacientes quanto às cores utilizadas no ambiente de terapia intensiva, identificando aquelas consideradas agradáveis e desagradáveis. Trata-se de pesquisa descritivo-exploratória, com enfoque quanti-qualitativo. A amostra foi constituída de clientes internados e profissionais que trabalham em três UTIs de hospitais públicos localizados em Goiânia. As cores consideradas mais agradáveis para serem utilizadas em UTI foram o azulclaro e o verde-claro. Além dessas, apontaram o amarelo-claro, palha, cinza, rosa e goiaba. $O$ vermelho e o preto foram consideradas as cores mais desagradáveis para um ambiente de UTI. Os profissionais e clientes referem preferência por cores variadas, as quais podem ser utilizadas no sentido de melhorar o clima da UTI.

\section{DESCRITORES}

Percepção de cores.

Ambiente de instituição de saúde. Unidades de Terapia Intensiva. Hospitais públicos.

\section{ABSTRACT}

The use of colors in the environment of an Intensive Care Unit (ICU) may interfere in the welfare of both professionals and patients. This study is aimed at analyzing the perceptions of professionals and patients regarding the colors used in the intensive care environment, identifying those considered pleasant and unpleasant. This is a descriptive-exploratory research with a quantitativequalitative focus. The sample was comprised of hospitalized patients and professionals at three public hospitals ICUs in the city of Goiânia, State of Goiás. The colors considered most pleasant for ICUs were light blue and light green. Light yellow, beige, gray, pink and guava were also pointed out as pleasing. Red and black were appointed as the most unpleasant. Professionals and patients demonstrated preference for varied colors, something that can be used as a way of improving the atmosphere of ICUs.

\section{RESUMEN}

La utilización de los colores en el ambiente de la Unidad de Cuidados Intensivos - UCI puede interferir en el bienestar de los profesionales y clientes. En este estudio se tuvo como objetivo analizar las percepciones de profesionales y pacientes en cuanto a los colores utilizados en el ambiente de cuidados intensivos, identificando aquellas consideradas agradables y desagradables. Se trata de una investigación descriptivo-exploratoria, con enfoque cuanti-cualitativa. La muestra estuvo constituida de clientes internados y de profesionales que trabajan en tres UCIs de hospitales públicos localizados en Goiânia. Los colores considerados más agradables para ser utilizadas en UCI fueron el celeste y el verde claro. Además de ellos, señalaron el amarillo, paja, gris, rosado y guayaba. El rojo y el negro fueron considerados los colores más desagradables para un ambiente de UCI. Los profesionales y clientes refirieron preferencia por colores variados, los cuales pueden ser utilizados en el sentido de mejorar el clima de la UCI.

\section{KEY WORDS}

Color perception.

Health facility environment.

Intensive Care Unit.

Hospitals, public.

\section{DESCRIPTORES}

Percepción de color.

Ambiente de instituciones de salud.

Unidades de Terapia Intensiva. Hospitales publicos.
1 Enfermeiro intensivista do Hospital de Clínicas da Universidade Federal de Goiás (UFG) e do Hospital de Doenças Tropicais do Estado. nbarbosa@hc.ufg.br 2 Enfermeira e

psicóloga. Gerente de enfermagem do serviço de urgência pediátrica do Hospital de Clínicas da UFG e intensivista do Hospital Geral de Goiânia.

3 Professora Doutora

da Faculdade de Enfermagem da UFG. 


\section{INTRODUÇÃO}

As cores exercem grande influência no ambiente, modificando-o, animando-o ou transformando-o, e assim, podem alterar a comunicação, as atitudes e a aparência das pessoas presentes, pois todos nós temos reações às cores.

A utilização das cores para fins de cura é um processo não agressivo sobre o organismo, não é maléfica, não causa efeitos colaterais e não atua como agente de pressão sobre o corpo. A cromoterapia atua diretamente na base da doença, procurando restaurar o equilíbrio entre as energias vibratórias do corpo ${ }^{(1)}$. A todo instante estamos em contato com as cores, elas fazem parte da vida e, sem elas, o mundo seria diferente.

A cromoterapia é uma ciência que usa a cor para estabelecer o equilíbrio e a harmonia do corpo, da mente e das emoções, sendo utilizada pelo homem desde as antigas civilizações. Os egípcios adotaram o poder de cura do sol e construíram templos adornados de cores e luz para os doentes. Os Incas no México, também adoravam o sol ${ }^{(2)}$. A mitologia considera a luz do espectro solar como fonte de longevidade, saúde e cura. Utilizado de forma adequada, hoje o sol se constitui em um elemento que complementa a prevenção e cura das doenças, sendo então reconhecido como meio terapêutico $^{(3)}$. As pessoas sentem grande prazer com a cor e o olho necessita da cor tanto quanto da luz ${ }^{(4)}$.

Os métodos mais conhecidos de tratamento com a cromoterapia são os banhos de luz; entretanto, existem outros também eficazes. Existem cores de pigmento ou cores de luzes, estas originadas de corpos de luz própria, como o sol ou lâmpadas coloridas. Já as cores de superfície não possuem energia radiante, tornam-se visíveis graças à iluminação. No cuidado o processo de expressão estética das cores pode ser através da mente, das lâmpadas coloridas, da dieta, da água solarizada, da luz solar, nas vestimentas e no ambiente através da decoração ${ }^{(5-6)}$.

De acordo com os pressupostos teóricos ${ }^{(7)}$, o ser humano é um todo unificado o qual possui uma integridade individual e manifesta características que são mais e diferentes que a soma de suas partes. Também, o indivíduo e o ambiente estão continuamente trocando matéria e energia entre si, sendo o ambiente um campo de energia irredutível, pandimensional, identificados por padrões que integra o campo humano. Para ela, o processo de vida dos seres humanos evolui, irreversivelmente e em uma única direção, ao longo do espaço-tempo. Em relação aos padrões de vida, expõe que são a identificação dos indivíduos e o reflexo de sua totalidade. Colocando ainda que o ser humano caracteriza-se pela capacidade de abstração e visualização, linguagem e pensamento, sensibilidade e emoção.

A natureza está sempre em busca de equilíbrio, a nossa existência é caracterizada por dualidades, havendo o masculino e o feminino, o positivo e o negativo, o claro e escuro, dentre outros contrastes. Nas cores também existem as polaridades, como cores frias e cores quentes. O vermelho é considerado cor quente e o azul, cor fria. Quanto mais quente for considerada a cor, mais vermelho ela contém. Quanto mais fria, mais azul ela possui, sendo esta consideração simbólica, mas real, quando aplicada à cura ${ }^{(8)}$.

Na área de saúde a aplicação de cores precisa ser adequada para transmitir a sensação de maior bem estar para o paciente, família e profissionais. Trabalhos científicos já verificaram a influência da estética do ambiente, no bem estar geral dos pacientes e da equipe médica ${ }^{(9)}$, apontando para a importância de cores dentro do ambiente da Unidade de Terapia Intensiva (UTI) que se não utilizadas adequadamente, podem contribuir como fator de estresse.

A questão da estética é um caminho a considerar e que preconiza o cuidado atribuído as condições do ambiente. Os profissionais de saúde devem procurar e implantar medidas que favoreçam a promoção do bem-estar físico e emocional deles mesmos, assim como da sua equipe, dos pacientes e familiares, incluindo a melhoria no ambiente de trabalho, onde é fundamental a preocupação com as cores neste local ${ }^{(10)}$.

Entretanto, percebe-se que a escolha da cor a ser utilizada no ambiente hospitalar, e especialmente nas Unidades de Terapia Intensiva, não se baseia na preferência daqueles que se inter-relacionam neste meio. Deste modo, considera-se oportuno investigar quais são as cores consideradas agradáveis e desagradáveis por parte de profissionais e clientes, verificando, inclusive, se estas coincidem ou não com aquelas presentes nos ambientes de UTI.

A preocupação com a utilização adequada das cores para os ambientes, inclusive na Unidade de Terapia Intensiva, deveria existir já no processo de construção dos hospitais.

Para os pacientes internados e profissionais que ali trabalham, a UTI é um espaço restrito, único, pequeno e tenso, o que interfere no estado emocional do indivíduo, levando ao desgaste geral do organismo e consequentemente, provocando estresse $^{(11)}$. Isto vendo o fato de permanecer durante horas em uma área de muito sofrimento e pouco atrativa em termos de decoração.

O contato apenas com cores monótonas ou que lembram doenças, morte, podem interferir nas questões físicas e nos 
aspectos emocionais e psicológicos, tanto de forma consciente quanto inconsciente. Desta forma, a harmonia das cores nos mobiliários, roupas, paredes, piso, teto e na decoração dos serviços de saúde é relevante, especialmente se considerarmos o período de internação da maioria dos pacientes e de trabalho dos profissionais.

Apesar de ser reconhecida a importância das cores na vida das pessoas, poucos trabalhos referentes à aplicação de cores no ambiente hospitalar foram encontrados na literatura $^{(9,12)}$, onde quase sempre o indivíduo sofre de várias privações sensoriais, entre elas a agradabilidade visual .

Artifícios simples, como a aplicação de cor adequada ao ambiente, podem amenizar o estado de estresse das pessoas internadas ou que trabalham em Unidades de Terapia Intensiva, justificando a realização de estudos que se preocupem com essa temática.

\section{OBJETIVOS}

Analisar percepções de profissionais e clientes quanto às cores utilizadas no ambiente de terapia intensiva, identificando as cores consideradas agradáveis e desagradáveis dentro das Unidades de Terapia Intensiva.

\section{METODOLOGIA}

A pesquisa é do tipo descritivo-exploratória, realizada em Unidades de Terapia Intensiva para adultos de três hospitais de grande porte da rede pública de assistência à saúde, localizados no município de Goiânia - GO.

A população constituiu-se de 3 médicos, 7 enfermeiros, 17 técnicos de enfermagem, 1 fisioterapeuta e 1 nutricionista que estavam trabalhando, e 10 clientes nas Unidades de Terapia Intensiva dos hospitais selecionados para o estudo. Foram incluídos na amostra, os profissionais que atuam nas UTIs há pelo menos seis meses, que estiveram trabalhando no período de coleta destinado à realização das entrevistas e os clientes que se encontravam internados nas UTIs e estavam orientados, conscientes e em plena condição de verbalização. Fazendo um total de 29 profissionais e 10 clientes.

Para a coleta de dados foi utilizada a entrevista semiestruturada que tem como característica valorizar a presença do entrevistador e dar liberdade e espontaneidade para o entrevistado, levando a um enriquecimento da investigação ${ }^{(13)}$ Esta foi dirigida aos profissionais e clientes, respeitando a disponibilidade dos sujeitos. A coleta de dados foi realizada no período de fevereiro a abril de 2004.

Foram feitas as seguintes questões: $\mathrm{O}$ que acha das cores utilizadas nas paredes, teto, piso, móveis e vestuário da Unidade de Terapia Intensiva? Quais cores você acha que deveriam existir dentro do ambiente da Terapia Intensiva? Quais cores você considera agradáveis dentro da Unidade de Terapia Intensiva? Quais as cores que você considera desagradáveis dentro da Unidade de Terapia Intensiva? Você gostaria de estar em contato com outras cores, além daquelas que estão presentes neste ambiente?

Entre os aspectos éticos observados consta a aprovação do projeto pelo Comitê de Ética em Pesquisa Médica Humana e Animal do Hospital das Clínicas da Universidade Federal de Goiás, protocolo $n^{\circ} 131 / 03$, e a assinatura do Termo de Consentimento Livre e Esclarecido por todos os que participaram da pesquisa, conforme recomendação Resolução $n^{\circ} 196 / 96$, referente à pesquisa envolvendo seres humanos $^{(14)}$. O consentimento das instituições participantes também foi previamente adquirido.

\section{RESULTADOS E DISCUSSÃO}

As cores exercem influência sobre as emoções e sentimentos. Podemos experimentar sensações de tristeza, alegria ou apreensão. As mudanças emocionais podem desencadear-se de acordo com a associação que fazemos com as cores, provocando também reações espontâneas, não pensadas $^{(15)}$. Por isso, quando se usam cores certas o equilíbrio e a harmonia são gradativamente restaurados. O objetivo do cuidado utilizando as cores no indivíduo e no meio ambiente é a busca da harmonia das energias das cores nestes ${ }^{(6)}$.

O gráfico 1 apresenta o percentual de representatividade da amostra participante do estudo.

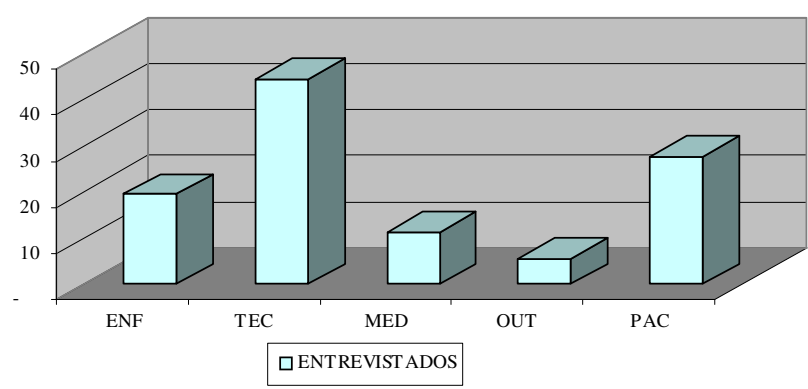

ENF - enfermeiro. TEC - técnico de enfermagem. MED - médico. OUT - outros profissionais. PAC - pacientes.

Gráfico 1 - Percentual de profissionais e pacientes entrevistados quanto às suas percepções sobre as cores no ambiente de UTI, Goiânia - 2004

A participação de técnicos de enfermagem no estudo foi de $44 \%$, seguida de um percentual de $28 \%$ de pacientes, $19 \%$ de enfermeiros, $11 \%$ de médicos e $6 \%$ de outros profissionais.

É importante que o ambiente apresente-se agradável a quem nele permanece. As cores consideradas mais agradáveis pelos pacientes e pelos profissionais que atuam em UTI foram o azul claro, o verde claro e o branco, conforme relatos a seguir: 
Branco e azul, bem claro transmitem harmonia, é menos pesado. (E1)

Cores claras, o azul do relógio. (E4)

O branco do teto. (E11)

O azul claro é agradável, não há azul claro. (E9)

A cor branca está associada entre outros aspectos, à simplicidade, limpeza, paz, pureza, harmonia, estabilidade ${ }^{(16)}$.

O verde é uma cor fria, aliviando e acalmando tanto física quanto mentalmente. Pode, primeiramente, exercer um efeito benéfico, mas depois de algum tempo torna-se fatigante. É a cor do nitrogênio um dos componentes mais presentes na atmosfera, ajuda a formar os músculos, os ossos e as células de outros tecidos. O verde atua sobre o sistema nervoso simpático, além de aliviar a tensão dos vasos sanguíneos e diminuir a pressão arterial. Ele é considerado como uma cor tranqüilizante, no ambiente de trabalho poderá ajudar na redução do estresse, porém deve ser utilizado com cautela porque com o tempo pode tornar-se cansativo ${ }^{(1)}$.

É conveniente pintar as paredes de azul em locais sujeitos a muita tensão, atritos e desavenças, pois esta cor proporciona um ambiente calmo e organizado em residências ou locais de trabalho. O azul é indicado para hospitais e clínicas, entretanto, pode tornar o ambiente frio, por isto deve ser usado com cuidado e discernimento. Além disso, a cor azul reduz o stress e a tensão, podendo, também, induzir ao sono e à depressão(15,17).

A cor azul é de todas as cores, a mais tranqüilizadora. Faz com que o cérebro secrete onze hormônios neurotransmissores que possuem ação tranqüilizante. Esses hormônios são sinais químicos que podem atuar acalmando todo o corpo ${ }^{(2)}$.

O gráfico 2 apresenta o percentual de cores consideradas mais agradáveis dentro da UTI, segundo as percepções de profissionais e pacientes dos serviços pesquisados.

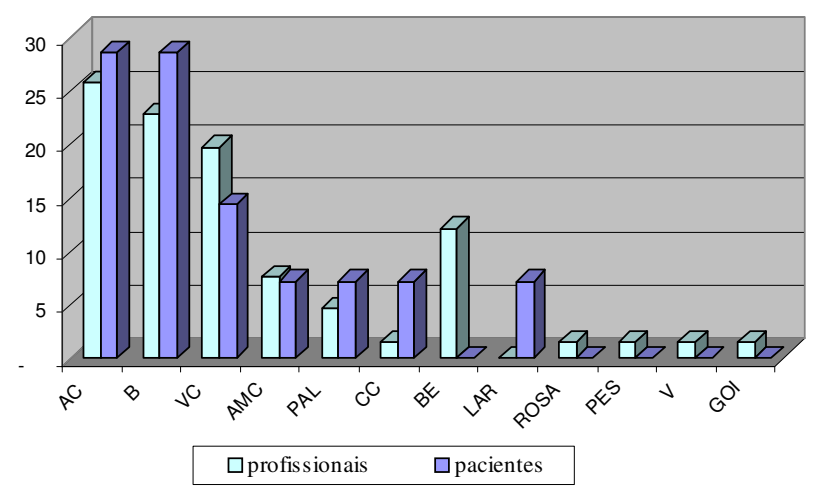

AC - azul claro; B - branco; VC - verde claro; AMC - amarelo claro; PAL - palha; CC - cinza claro; BE - bege claro; LAR - laranja; ROSA - rosa; PES - pêssego; V - vinho; GOI - goiaba.

Gráfico 2 - Percepções de profissionais e pacientes quanto às cores que consideram agradáveis dentro da UTI, Goiânia 2004
A cor azul claro foi referida por $26 \%$ dos profissionais e $29 \%$ dos pacientes, o branco por $23 \%$ e $29 \%$, o verde claro $20 \%$ e $14 \%$, o amarelo claro $8 \%$ e $7 \%$ e palha $5 \%$ e $7 \%$, respectivamente. Outras cores também foram citadas pelos profissionais como: bege (12\%) e pêssego, cinza claro, rosa, vinho e goiaba, totalizando $2 \%$ das opiniões. Os pacientes referiram ainda as cores: cinza (7\%) e laranja (7\%).

O discurso dos sujeitos demonstra sua preferência de cores:

O laranja e amarelo como contraste. A cor palha dá idéia de profundidade. (E7)

Amarelo para chamar a atenção. (E14)

O bege da parede é melhor que branco. O branco é muito neutro. (E6)

São agradáveis o bege da parede, o azul do respirador e o verde do bird. (E12)

Um espaço com amarelo torna-se quente e expansivo, ativando a mente e abrindo-a para novas idéias. A cor amarela torna a pessoa mais sensível à consciência e deixandoa mais alerta. Além disso, auxilia também aqueles que possuem dificuldade para aprendizagem. Aplicado em passagens, corredores e lugares onde existe pouca luz, o amarelo pode proporcionar uma sensação de maior espaço ${ }^{(15)}$.

A cor amarela influencia o sistema nervoso simpático e parassimpático, aumenta a pressão arterial, pulsação e respiração, tal como o vermelho, embora de forma menos estável. Veículos (principalmente avião) com o interior pintado de amarelo, produzem enjôo nos passageiros. É também considerado como um restaurador dos nervos ${ }^{(16)}$.

A vivacidade, a alegria, o desprendimento e a leveza, estão relacionados à cor amarela. Produzindo relaxamento, desinibição, brilho, reflexibilidade, alegria espirituosa e espiritualidade. Age como antidistônica, levando a um grau de equilíbrio entre o sistema nervoso simpático e parassimpático. Aumenta a pressão arterial, reduzindo a produção de ácidos $\operatorname{graxos}^{(2)}$.

O laranja é uma cor que também aumenta o apetite, mas, induz o relaxamento e aumenta o potencial para o sono, ao diminuir a freqüência do fluxo sanguíneo ${ }^{(2)}$.

Atualmente, nos hospitais percebe-se a necessidade de mudanças e preocupação em alegrar os ambientes. Os tons pálidos de cinza, assim como o branco e o creme, juntos com uma cor vibrante, realçam as cores, podendo ser eficazes no ambiente hospitalar $^{(15)}$.

Dependendo das características do ambiente, seus cheiros, suas cores e a decoração, podem tornar o local desagradável. Quanto a isto, foram encontradas opiniões diversas, as quais são apresentadas a seguir: 
Preto, vermelho e branco cansa. Desde que haja outras cores compondo, o branco pode ser usado fazendo parte do contraste. Jamais pintar uma parede de branco. (E4)

São desagradáveis, o roxo, preto e todas as cores escuras com exceção do vermelho para algumas coisinhas. (E9)

Cores fortes, escura e pesada como verde e marrom. (E20)

Cores com tons fortes, preto, vermelho, e amarelo ouro. Branco sozinho. (E16)

O preto do rodapé não agrada. (E11)

O piso chumbo com preto que está na copa e no vestuário.

O gráfico 3 apresenta as cores consideradas mais desagradáveis no ambiente de UTI, pelos profissionais e clientes. A cor preta foi referida por $24 \%$ dos profissionais e $50 \%$ dos pacientes, o vermelho por $18 \%$ e $33 \%$, respectivamente. Os profissionais ainda citaram as cores: verde escuro (10\%), amarelo escuro e marrom (8\%), azul escuro (7\%), branco, cinza e roxo (6\%), bege (4\%) e rosa, cinza escuro e lilás (1\%). O branco foi considerado uma cor desagradável por $17 \%$ dos pacientes.

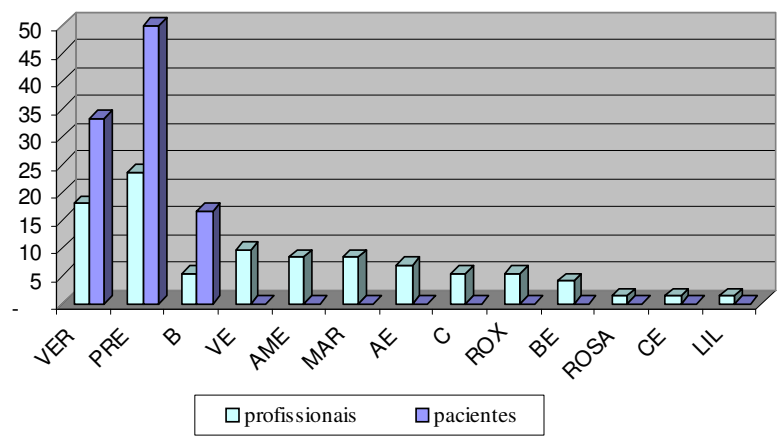

VER - vermelho; PRE - preto; B - branco; VE - verde escuro; AME - amarelo escuro; MAR - marrom; AE - azul escuro; $\mathrm{C}$ - cinza; ROX - roxo; BE - bege; ROSA - rosa; CE - cinza escuro; LIL - lilás.

Gráfico 3 - Percepções de profissionais e pacientes quanto às cores que consideram desagradáveis dentro da UTI, Goiânia 2004

A cor preta possui o espectro de cor completa e está associada à sujeira, sombra, enterro, morte e fim, podendo despertar sentimentos de maldade, miséria, pessimismo, dor, temor, negação, melancolia e angústia ${ }^{(16)}$. Se utilizado com outra cor torna-se imponente. Porém pode induzir à indiferença, inacessibilidade e prepotência ao extremo ${ }^{(15)}$.

Em relação à utilização do vermelho no ambiente, os tons escuros podem ativar a violência contida nas pessoas, excita as tendências básicas, estimulando o indivíduo a agir antes de pensar. Por estimular o apetite e fazer a pessoa perder a noção de tempo, são utilizados em restaurantes, bares, teatros e cassinos ${ }^{(15)}$.
O excesso de amarelo pode levar a indigestão, gastrites e úlceras gástricas ${ }^{(16)}$. As cores bege, branca, cinza e rosa, que aparecem como agradáveis no gráfico 2 , também foram consideradas desagradáveis por algumas pessoas, como mostra o gráfico 3 e os relatos a seguir:

\section{O bege escuro da parede é uma cor mais forte, se ficar olhando direto cansa. É a cor do corredor, não seria ideal para o quarto dos pacientes, mas é bom para os funcio- nários. (E25)}

As cores na UTI sempre tem cinza e branco, cores mortas, horrível. (E9)

Bege na parede é melhor que branco. O branco é muito neutro. (E13)

Outras cores são melhores, comparadas ao branco. (E28)

A literatura refere que um ambiente totalmente branco é tão atemorizador quanto um preto ${ }^{(18)}$. Quando se trabalha com ansiedade e preocupação, qualquer cor no ambiente com os tons quentes e fortes, potencializa esses sentimentos, e devem ser evitadas. Uma parede vermelha pode deixar as pessoas mais ansiosas e irritadas ${ }^{(16)}$. Sendo assim, um estímulo pode se tornar estressor em função da interpretação e do significado que o individuo atribui ${ }^{(19)}$.

Além dos pacientes e profissionais terem referido cores que consideram agradáveis, eles também citaram outras cores que gostariam de estar em contato no ambiente de trabalho. Estas percepções estão apresentadas no gráfico 4.

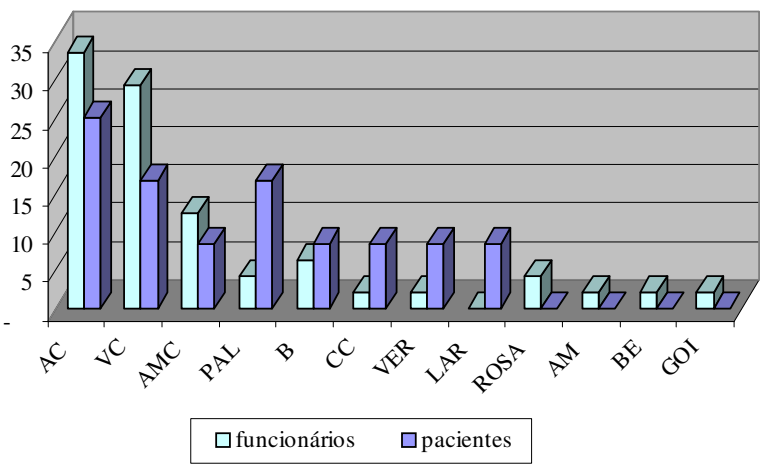

AC - azul claro; VC - verde claro; AMC - amarelo claro; PAL - palha; B - branco; CC - cinza claro; VER - vermelho; LAR - laranja; ROSA - rosa; AM - amarelo; BE - bege claro; GOI - goiaba.

Gráfico 4 - Percepções de profissionais e pacientes quanto às cores que gostariam de estar em contato além daquelas que estão presentes no ambiente da UTI, Goiânia - 2004

As cores azul claro, verde claro, amarelo claro e palha foram consideradas por profissionais e pacientes como as mais agradáveis e, além disso, destacadas como aquelas que gostariam de estar em contato dentro do ambiente da UTI.

Gostaria de verde, azul e amarelo em tons claros. (E22) 
Cinza bem claro, pois é uma cor agradável. Que tivesse algumas cores que puxasse para o verde. Nos quartos poderia ter alguma cor verde. Detalhes coloridos, principalmente tendo o verde no ambiente. (E15)

Verde água nos lençóis. (E12)

Dentro dos tons claros alternar azul e verde claro. (E6)

O gráfico 4 demonstra que, além das cores existentes, pacientes e profissionais gostariam de estar em contato com azul claro (33\%) para os profissionais e $(25 \%)$ para os pacientes, verde claro (29\%) e (17\%), amarelo claro (12\%) e (8\%), a cor palha (4\%) e (17\%), branca (6\%) e $(8 \%)$, cinza e vermelha $(2 \%)$ e $(8 \%)$, respectivamente. Os profissionais também referiram preferência pelas cores bege $(8 \%)$, rosa $(8 \%)$, amarelo e goiaba $(2 \%)$.

$\mathrm{O}$ verde atua no sistema nervoso como sedativo e colabora com pessoas com insônia, esgotamento e irritação. Age como harmonizador emocional e estimulante da pituitária $^{(8)}$.

Além de reduzir a pressão sanguínea, a cor azul inibe a descarga de adrenalina e age como hipnótico sobre o sistema nervoso central, estimula atividades intelectuais e a meditação. É uma cor passiva, concêntrica, perceptiva, sensível, incorporativa e unificadora, representa suavidade, tranqüilidade e ternura, trazendo segurança e $\operatorname{paz}^{(2,17)}$.

Os pacientes referiram preferência também pela cor laranja (8\%). A utilização desta cor no ambiente estimula as pessoas a despertar para os seus potenciais, se tornando mais confiantes. Estimula a comunicação, a criatividade, a afetividade e a vitalidade ${ }^{(5)}$.

Quando uma pessoa é exposta ao vermelho há um sinal químico que vai da glândula pituitária até a glândula adrenal havendo a liberação de epinefrina e causando alterações fisiológicas com efeitos metabólicos, isto acarreta aumento da pressão sanguínea, do pulso, da freqüência respiratória, do apetite e do olfato, há uma predominância do sistema nervoso autônomo e as reações tornam-se automáticas ${ }^{(2)}$.

A cor branca, considerada uma das mais agradáveis e que deveria existir na UTI, não aparece com um percentual significativo, talvez por estar presente com maior freqüência nos ambientes hospitalares.

\section{CONSIDERAÇÕES FINAIS}

As cores possuem significados próprios de acordo com cada indivíduo, grupo, país e cultura, fazendo com que sejam relacionadas a sentimentos, comportamentos, ações, experiências, ambientes ou acontecimentos específicos de seu passado. Em decorrência disto, o cuidado através das cores é um processo individualizado, observando a necessidade de cada pessoa e as diferentes formas de reação às cores $^{(6)}$.

Cada cor produz um efeito no ser humano, interferindo no físico e, dependendo do espectro, influenciando na mente e na emoção. Na área da saúde, a influência das cores no ambiente terapêutico já vem se configurando como uma preocupação $^{(9,12)}$.

Os profissionais que se encontravam trabalhando e os pacientes internados nas Unidades de Terapia Intensiva, referiram que as cores mais agradáveis e presentes neste ambiente eram o azul claro, o branco e o verde claro. Além das cores existentes, apontaram as cores amarelo claro, palha, cinza, rosa e goiaba como aquelas que também gostariam de estar em contato no ambiente da UTI.

Cores como o preto e o vermelho foram consideradas, tanto por pacientes, quanto por profissionais, como desagradáveis e impróprias para a UTI. Além disso, alguns clientes referiram que a cor branca, usualmente utilizada nos serviços de saúde, torna-se desagradável dentro do ambiente de terapia intensiva.

A cor é um evento que pode estar sendo ou não interpretado e significado pelo indivíduo. Tanto em um como em outro momento a cor pode ser um fator estressor. Pois ela pode estar agindo como um estímulo insistente sobre a pessoa causando estresse pela sua constância ${ }^{(19)}$.

Se considerarmos que as pessoas passam grande parte de suas vidas no ambiente de trabalho, os serviços de saúde também deveriam se preocupar com as questões relativas às cores e a estética deste local. Além disso, um ambiente agradável pode amenizar sensações de dor, sofrimento, tristeza e preocupação, as quais acompanham a maioria dos clientes que necessitam permanecer internados nas unidades de assistência à saúde.

Por fim, na Unidade de Terapia Intensiva as pessoas não são insensíveis às cores, profissionais e pacientes descrevem, segundo suas próprias percepções, as sensações transmitidas pelas cores neste ambiente. Os ambientes animados e inanimados estão unificados pelos campos de energias, estes são abertos fazendo com que haja troca entre eles ${ }^{(7)}$. Sendo assim, especial atenção necessita ser voltada à aplicação de cores e suas diferentes tonalidades no setor da UTI, considerando, inclusive, que as cores com seus campos de onda, não somente decoram, mas também podem contribuir para o bem estar das pessoas que estão em contato com este ambiente. 


\section{REFERÊNCIAS}

(1) Amber R. Cromoterapia: aura através das cores. São Paulo: Cultrix; 2000

(2) Walker M. O poder das cores: as cores melhorando a sua vida. Tradução de Denise Cavalcante. São Paulo: Saraiva; 1995.

(3) Biazzi EMS. Recursos para uma vida natural. São Paulo: Casa Publicadora Brasileira; 1999.

(4) Goethe JWV. Doutrina das cores. Apresentação, seleção e tradução Marco Gianote. São Paulo: Nova Alexandria; 1993.

(5) Vollmar K. O poder das cores. Tradução de Werner Leyen. Porto Alegre: Kuarup; 1997.

(6) Silva A. O cuidado através das cores. Rev Baiana Enferm. $2000 ; 13(1 / 2) 17-28$

(7) George JB. Teoria de enfermagem: os fundamentos à prática profissional. Tradução de Ana Maria Vasconcelos Thorell. Porto Alegre: Artes Médicas Sul; 2000.

(8) Andrews T. A cura pela cor. São Paulo: Estampa; 1989.

(9) Santos V. Um novo conceito de Centro de Tratamento Intensivo: a ergonomia na humanização e otimização dos espaços. Rev Bras Ter Intensiva. 1994;6(3):66-9.

(10) Hoga LAK. A dimensão subjetiva do profissional na humanização da assistência à saúde: uma reflexão. Rev Esc Enferm USP. 2004;38(1):13-20.
(11) Martino MMF, Misko MD. Estado emocionais de enfermeiros no desempenho profissional em unidades críticas. Rev Esc Enferm USP. 2004:38(2):161-7.

(12) Jatene H. Arquitetura para médicos: planejar um consultório, clínica ou hospital exige especialização. Rev Diálogo Méd. 1999;14(6):18-20.

(13) Triviños ANS. Introdução à pesquisa em ciências sociais: a pesquisa qualitativa em educação. São Paulo: Atlas; 1987.

(14) Brasil. Ministério da Saúde. Conselho Nacional de Saúde. Comissão Nacional de Ética em Pesquisa - CONEPE. Resolução n 196/96. Dispõe sobre a pesquisa envolvendo seres humanos. Brasília; 1996.

(15) Lacy ML. O poder das cores no equilíbrio dos ambientes. São Paulo: Pensamento; 2000

(16) Farina M. Psicodinâmica das cores em comunicação. São Paulo: Edgard Blücher; 1990.

(17) Bontempo M. Os efeitos das cores. In: Claret M. O poder da cromoterapia. São Paulo: Martin Claret; 1998.

(18) Guimbel T. A energia curativa através das cores. São Paulo: Pensamento; 1995.

(19) Parafaro RC, Martino MMF. Estudo do estresse do enfermeiro com dupla jornada de trabalho em um hospital de oncologia pediátrica de Campinas. Rev Esc Enferm USP. 2004;38(2):152-60. 